\title{
Article
}

\section{Building a discipline: Indicators of expansion, integration and consolidation in design research across four decades}

Christensen, Bo T. and Ball, Linden

Available at http://clok.uclan.ac.uk/31344/

Christensen, Bo T. and Ball, Linden ORCID: 0000-0002-5099-0124 (2019) Building a discipline: Indicators of expansion, integration and consolidation in design research across four decades. Design Studies, 65 . pp. 18-34. ISSN $0142-694 X$

It is advisable to refer to the publisher's version if you intend to cite from the work. http://dx.doi.org/10.1016/j.destud.2019.10.001

For more information about UCLan's research in this area go to http://www.uclan.ac.uk/researchgroups/ and search for <name of research Group>.

For information about Research generally at UCLan please go to http://www.uclan.ac.uk/research/

All outputs in CLoK are protected by Intellectual Property Rights law, including Copyright law. Copyright, IPR and Moral Rights for the works on this site are retained by the individual authors and/or other copyright owners. Terms and conditions for use of this material are defined in the policies page.

\section{CLoK}

Central Lancashire online Knowledge www.clok.uclan.ac.uk

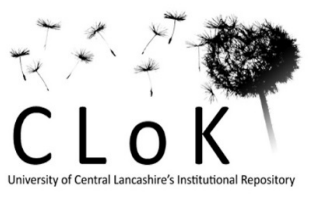


This is the final version of a manuscript that was published in Design Studies in November 2019. The published version of record may differ from this manuscript.

Building a Discipline: Indicators of Expansion, Integration and Consolidation in Design Research across Four Decades

\author{
Bo T. Christensen* \\ Department of Marketing \\ Copenhagen Business School \\ Solbjerg Plads 3, 2000 Frederiksberg C \\ Denmark \\ Phone: +4538152123 \\ Email: bc.marktg@cbs.dk
}

\title{
Linden J. Ball
}

School of Psychology

University of Central Lancashire

Preston PR1 2HE

UK

Phone: +44 (0)1772 893421

Email: LBall@uclan.ac.uk

* Corresponding Author 
Building a Discipline: Indicators of Expansion, Integration and Consolidation in Design Research across Four Decades

\begin{abstract}
Sparked by concerns with increased domain fragmentation in design research, we explored indicators of expansion, integration and consolidation in this area of inquiry through the lens of publications in Design Studies across the 40 years since the journal's inception. We examined several key indicators, including authors' disciplinary affiliations, levels of cross-disciplinary co-authorships, the increasing centrality of the term 'design' in stated university affiliations, the nature of citation patterns, the consolidation of core domain concepts over time and the role of esteemed authors as central 'curators' of design knowledge. We conclude that the Design Studies community has historically proven to be eminently capable of expanding its reach to new sub-disciplines through conceptual integration, whilst simultaneously consolidating the core foundation of design research.
\end{abstract}

Keywords: Design research, design knowledge, collaborative design, interdisciplinarity, science of design 


\section{Building a Discipline: Indicators of Expansion, Integration and Consolidation in Design Research across Four Decades}

After forty years of development in the theme of 'Design as a Discipline', now might be expected to be a time to look back at past successes and significant domain developments. However, as argued by notable scholars in our field (Bremner \& Rodgers, 2013; Cash, 2018; Cross, 2018; Dorst, 2011), design as a discipline may be facing troubles in the years to come. The discipline of design and the concept of 'design thinking', in particular, have seen an enormous expansion of interest in recent years coming from popular management and business books, major practitioner publications and new fields such as the health sciences and IT (Liedtka, 2015). The expansion of interest in design thinking often does not entail an awareness of the long history of research on the concept as reflected in the pages of the present journal, creating a problematic situation for a research community that traditionally shies away from oversimplifying its object of study and that customarily cherishes a multiplicity of perspectives (Dorst, 2011).

The growth of interest in design research has extended in multiple directions and is of such a magnitude that one might be worried about whether our research community will survive the storm of interest. Is design research at risk of breaking into pieces of disintegrated design understanding (Cross, 2018a; Dorst, 2011)? As design research extends and evolves into new hybrid forms utilizing multiple disciplinary perspectives, we might see once well-recognized and discrete design disciplines becoming diluted (Bremner \& Rodgers, 2013), potentially leading to a loss of conceptual coherence (Cash, 2018). Perhaps we are in need of a more coordinated and progressive research programme to counter this fragmentation (Cross, 2018a)? Perhaps we should be worrying about the integrative capacities of our community - and the present journal - to avoid any looming separation into echochambers of disconnected knowledge? Sparked by such concerns, we decided to use the opportunity of contributing to a special review issue of Design Studies as a means to explore indicators of expansion, integration and consolidation in design research through the vehicle of publications that have appeared in the journal across its lifetime.

The history of design research as published in Design Studies has proven to be fundamentally multidisciplinary in nature, with a multitude of (sometimes shifting) disciplinary lenses being directed towards the study of design and designing. To explore the integrative capacities of this premier journal in design research over a 40-year timespan we set out to examine the articles published in the journal to gain a clearer understanding of the disciplines that have been involved in 
the reported research and to render visible evidence of domain expansion and pointers toward conceptual integration as opposed to fragmentation. Our article is thus less about what has been learned about design in the past 40 years, and more about how (and with whom) we have learned and collaborated as researchers across disciplines in the process. The article therefore adopts a descriptive approach and aims to overview the multitude of disciplinary backgrounds that are associated with the community of researchers that make up the authors of Design Studies articles. We also explore citation data for articles published in the journal as a way to index the extent and reach of knowledge and understanding. Our approach is, perhaps, a little unusual, but given the scope of the task of overseeing developments across four decades of design research we prefer to avoid recourse to a standard qualitative literature review and instead turn to the selective analysis of key indicators of expansion, integration and consolidation as seen through author affiliations and citation patterns in Design Studies across time.

We contend that the history of Design Studies is also a story of the making of a new discipline of design research. New disciplines do not come into existence overnight. Consider, for example, the advent of 'cognitive science' as a progressively autonomous academic discipline. Consensually, the establishment of cognitive science has been dated to around 1956 - and some even set the date more precisely to a symposium on information theory held at the Massachusetts Institute of Technology (MIT) on the $11^{\text {th }}$ September 1956. Attending the symposium were scholars such as George Miller, Noam Chomsky, Allan Newell, and, of course, Herbert Simon, who had yet to write the design research classic 'Sciences of the Artificial' (published in 1969). Writing on the establishment of cognitive science some 28 years later, Howard Gardner (1987) traced the history of the coming into being of this new discipline to notable theoretical, methodological and technological developments in a string of distinct 'mother' disciplines, notably philosophy, psychology, artificial intelligence, linguistics, anthropology and neuroscience. In cognitive science, elements of each field were brought together in new ways, which led to the emergence of a so-called cognitive revolution.

Writing in 1987, however, Gardner commented that even close to thirty years after the advent of cognitive science there was still some way to go for it to achieve the status of a discipline proper, noting that most work in cognitive science was still taking place under the umbrella of one of the mother disciplines, for example, as a sub-unit to a psychology department, rather than as the interdisciplinary endeavor it was envisioned to be. Even today, some 65 years into what Gardner (1987) evocatively badged as the 'mind's new science', most cognitive science research is still practiced at departmental level under the banner of a traditional mother discipline, while 
interdisciplinary cognitive science departments are much less prevalent. The point that we would like to draw from this analysis is that the establishment of new disciplines out of old ones within universities takes time and the scope and challenge of such an endeavor should not be underestimated!

Drawing further parallels with the advent of cognitive science as a new discipline, we contend that the 1962 'Conference on Design Methods', which was held in London in 1962 (Jones \& Thornley, 1963), was arguably our own MIT 'Information Theory Symposium' moment, constituting the birth of design research. As Cross (2007) notes, this conference is generally regarded as the event that marked the launch of design methodology as an important subject of enquiry, a subject which subsequently broadened and evolved through the 1960s and 1970s to become a far more encompassing field of research relating to design methodology, design theory and design practice, with an ever-increasing interest in empirical studies of cognition, communication and collaboration in design.

Yet another critical moment in the development of the field of design research was undoubtedly the emergence of the first journal of design research, with the initiation of Design Studies in 1979 by the Design Research Society, which was itself established in 1966. In the very first issue of Design Studies, Bruce Archer (1979) wrote an article outlining the field of design entitled 'Design as a Discipline'. He noted that design is: “...equated with Science and the Humanities, is defined as the area of human experience, skill and understanding that reflects man's concern with the appreciation and adaption to his surroundings in the light of his material and spiritual needs. In particular, though not exclusively, it relates with configuration, composition, meaning, value and purpose in man-made phenomena' (Archer, 1979, p. 20). Thus, from the outset, design research was conceptualized - like cognitive science - as an interdisciplinary constellation of contributing disciplines. In what follows below we explore how design research - as reflected in articles appearing in Design Studies over the past 40 years - has both expanded into disciplines and integrated them across time.

\section{Methods}

To investigate the disciplinary backgrounds of authors of Design Studies papers we decided to use authors' listed department-level, faculty'-level and university-level affiliations, restricting our analysis to full-length Design Studies articles. Admittedly, employment affiliation is just a proxy for

\footnotetext{
${ }^{1}$ We use the term 'faculty' as broadly interchangeable with other, related terms such as 'school' and 'college', whilst also being alert to the fact that the alignment of terms, whilst typical, is imperfect (e.g., sometimes a school will appear more similar to a single-subject department than a multi-subject faculty).
} 
the disciplinary perspective that authors may apply to their research in the design field. A change to another university by an individual author will frequently mean a change of their department title without necessarily changing the author's disciplinary lens. Furthermore, department titles at universities are somewhat conservative and change at a rather slow pace, meaning that a sudden change of an individual author's disciplinary perspective on design is not likely to be visible in their listed affiliation, albeit university 'centre' and 'institute' constructions do sometimes hold innovative names that are more reflective of changing trends and emerging interdisciplinary endeavors. Nonetheless, whilst recognizing that departmental titles are a mere proxy, our hope with this exercise was to try to quantify which disciplines contribute their papers to Design Studies and to see whether this contribution has changed across each decade in the past 40-year timespan.

Our starting point was to categorize each of the 1514 authors' university affiliation into several crude disciplines (at department level), for all 1054 full-length Design Studies articles (excluding other types, such as editorials) for the 40 years from 1979-2018. Friedman (2003) listed six scientific domains of relevance to design that can also be sub-coded at department level (see Table 1), and to this list we added one further category prevalent in the data (i.e., company affiliation). The coding was applied by the first author, by primary reference to affiliation names at department level (i.e., 'Department of...'), but secondarily informed by faculty level (i.e., 'Faculty of...; 'College of...', 'School of...') or institution type ('University of the...'). Affiliations that did not allow for a clear categorization into one of the seven categories (e.g., due to only listing affiliation at overall University level) were coded as 'Not classifiable'. If all authors of an article were unclassifiable, the paper was excluded ( $n=$ 84). For co-authored papers, individual discipline and department coding was applied to each author's affiliation.

Table 1. Coding categories for author affiliations.

\begin{tabular}{|c|c|c|}
\hline Discipline & Sample Department Affiliations & Examples \\
\hline $\begin{array}{l}\text { Humanities and } \\
\text { Liberal Arts }\end{array}$ & $\begin{array}{l}\text { Philosophy } \\
\text { Communications Studies } \\
\text { Humanities } \\
\text { Media and Visual Arts } \\
\text { Design and Music } \\
\text { Performance and Cultural } \\
\text { Industries }\end{array}$ & $\begin{array}{l}\text { Department of Philosophy, Ryerson } \\
\text { University } \\
\text { Department of Media and Visual Arts, } \\
\text { Koc University }\end{array}$ \\
\hline $\begin{array}{l}\text { Social and } \\
\text { Behavioral } \\
\text { Sciences }\end{array}$ & $\begin{array}{l}\text { Psychology } \\
\text { Cognitive Science } \\
\text { Cultural Studies } \\
\text { Sociology } \\
\text { Praxiology }\end{array}$ & $\begin{array}{l}\text { Department of Psychology, University of } \\
\text { Nottingham } \\
\text { Department of Sociology, University of } \\
\text { Manchester }\end{array}$ \\
\hline
\end{tabular}




\begin{tabular}{|c|c|c|}
\hline Natural Science & $\begin{array}{l}\text { Natural Sciences } \\
\text { Mathematics }\end{array}$ & $\begin{array}{l}\text { Faculty of Mathematics, Open University } \\
\text { School of Natural Sciences, Technology } \\
\text { and Environmental Studies, Södertörn } \\
\text { University }\end{array}$ \\
\hline $\begin{array}{l}\text { Human } \\
\text { Professions and } \\
\text { Services }\end{array}$ & $\begin{array}{l}\text { Education } \\
\text { Management } \\
\text { Marketing } \\
\text { Business } \\
\text { Public Health } \\
\end{array}$ & $\begin{array}{l}\text { Department of Education, University of } \\
\text { Oslo } \\
\text { School of Business, Reykjavik University } \\
\text { College of Health Professions }\end{array}$ \\
\hline $\begin{array}{l}\text { Technology and } \\
\text { Engineering }\end{array}$ & $\begin{array}{l}\text { Mechanical Engineering } \\
\text { Industrial Design } \\
\text { Civil Engineering } \\
\text { Electrical and Computer } \\
\quad \text { Engineering } \\
\text { Engineering Education } \\
\text { Architecture, Building and Planning } \\
\text { Computer Science } \\
\text { Informatics } \\
\text { Software Engineering } \\
\text { Computing }\end{array}$ & $\begin{array}{l}\text { Department of Industrial Design, lowa } \\
\text { State University } \\
\text { Delft University of Technology, Faculty of } \\
\text { Civil Engineering } \\
\text { Computing and Information Studies, } \\
\text { Griffith University }\end{array}$ \\
\hline $\begin{array}{l}\text { Applied Art, } \\
\text { Design and } \\
\text { Architecture }\end{array}$ & $\begin{array}{l}\text { Design } \\
\text { Architecture } \\
\text { Applied Art } \\
\text { Art and Design }\end{array}$ & $\begin{array}{l}\text { Design Studies Department, Goldsmiths' } \\
\text { College } \\
\text { School of Architectural Studies, } \\
\text { University of Sheffield }\end{array}$ \\
\hline Company & $\begin{array}{l}\text { Auto Manufacturer } \\
\text { Military }\end{array}$ & $\begin{array}{l}\text { Air Force Operational Test and } \\
\text { Evaluation Center } \\
\text { IDEO Product Development }\end{array}$ \\
\hline Not Classifiable & $\mathrm{n} / \mathrm{a}$ & $\begin{array}{l}\text { University of Houston } \\
\text { Interactive Institute, Sweden }\end{array}$ \\
\hline
\end{tabular}

To allow for the tracing of new disciplines publishing in Design Studies, we applied the codes in chronological order, starting with the first 1979 Design Studies issue. This allowed for the use of the first decade of affiliations as the benchmark for subsequent decades of Design Studies author affiliations, whereby novel additions of discipline affiliations could be identified, speaking towards the possible disciplinary extension of design research across time as well as the possible changing composition of the disciplines publishing in the journal.

\section{Results}

\subsection{Disciplinary Affiliations}

The most prevalent disciplinary affiliations publishing in Design Studies in the past 40 years in descending order are: Technology and Engineering (59.5\%); Applied Art, Design and Architecture (32.7\%); Human Professions and Services (7.7\%); Social and Behavioural Science (7.3\%); Company (5.4\%); Humanities and Liberal Arts (4.8\%); and Natural Science (0.7\%). Due to co-authorships, each article may be classified in more than one category, which is why the percentages does not add up 
to $100 \%$. Looking across time, the percentage of Design Studies articles with author affiliations in the seven disciplinary categories are listed in Figure 1. The two most prevalent disciplinary categories are Technology and Engineering and Applied Art, Design and Architecture, which both display a constant high level of author affiliation across time, although with the first time-period 1979-1988 displaying a reduced level for Technology and Engineering. On the other hand, both Humanities and Liberal Arts and Social and Behavioural Science display increasing trends across time, with a constant low prevalence of author affiliation over time for Natural Science. Finally, no clear overall trend across time is evident for Company affiliations, while Human Professions and Services has shown an increase in the most recent period relative to both 1989-1998 and 1999-2008.
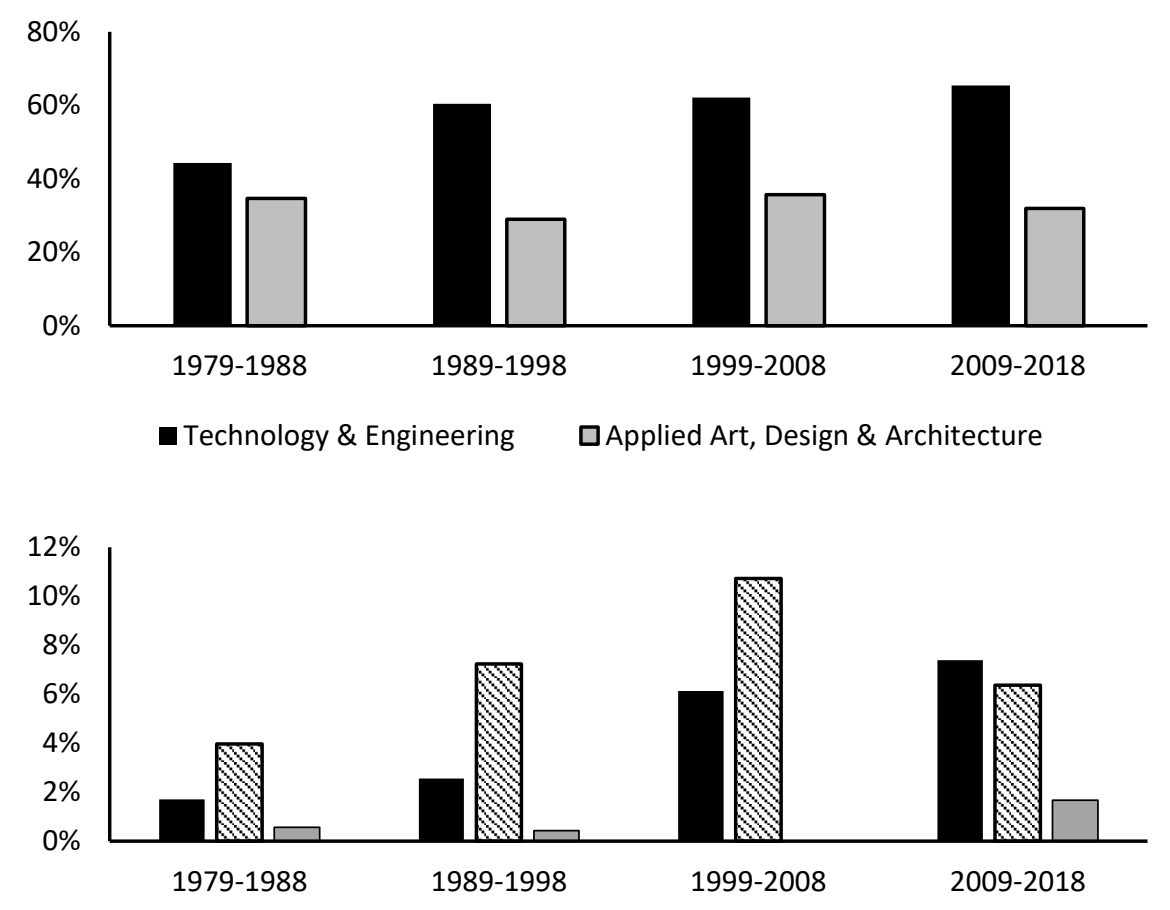

- Humanities and Liberal Arts $\mathbf{8}$ Social and Behavioral Sciences $\square$ Natural Science

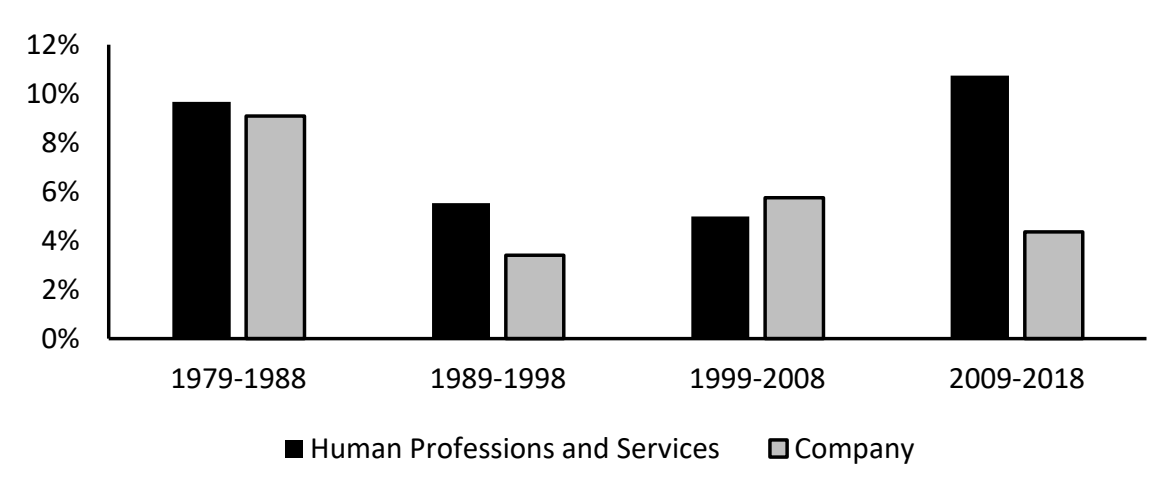

Figure 1. Percentage of Design Studies author affiliations by disciplinary category and decade. Note: The scale on the vertical axis of the lower two graphs is different to that of the upper graph to aid readability. 
The major impression that is formed when looking across time is one of a constant domination in author affiliations by researchers from the disciplines of Technology and Engineering and Applied Art, Design and Architecture. However, expansive trends in authorship affiliation are evident for researchers allied to other disciplines, most notably Humanities and Liberal Arts, Social and Behavioural Sciences and Human Professions and Services (e.g., professions allied to business and education). It is possible that such trends mirror the recent expansion of design research into new domains, but since the trends are depicted at the fairly crude level of overarching discipline areas, the data do not tell us whether the expansion comes from an increased level of authorship from subdisciplines that have always published in Design Studies, or whether entirely new sub-disciplines have started to publish in Design Studies across time. To explore this issue, we analyzed the decadeby-decade chronological order of sub-disciplinary affiliations to determine whether entirely new types of sub-disciplines appeared and the point of first appearance.

This latter, more nuanced exploration of the history of Design Studies author affiliation revealed that the benchmark decade of 1979-1988 already included most Technology and Engineering subdisciplines, especially industrial design, mechanical engineering and computer science as well as author affiliations with design departments at technical universities. Further, the Applied Arts, Design and Architecture category also included from the outset many of the dominant affiliations, especially to architecture departments and design schools. But the initial decade also included a few Humanities and Liberal Arts sub-disciplines (i.e., philosophy; art) and Social Science sub-disciplines (i.e., psychology; social policy; praxiology). In addition, a variety of authors who aligned with Human Professions and Services had already published in Design Studies in the first decade, including individuals linked to business schools who were affiliated with core sub-disciplines (i.e., marketing; management; operations management; organization and work science) as well as individuals linked to education departments. Company affiliations initially covered mainly research units at engineering or technology companies (e.g., IBM; Rolls-Royce; Dunlop), but also included military affiliations.

The second period from 1989-1998 saw the inclusion of a few new specialized Technology and Engineering sub-disciplines (e.g., robotics, Al and information systems) or cross-disciplinary departmental affiliations within Technology and Engineering (e.g., mechanical engineering and business organisation). A few new Humanities and Liberal Arts sub-disciplines (e.g., art history; electronic arts) and several new Social and Behavioural Science sub-disciplines (e.g., ergonomics; 
cognitive science; sociology; behavioral science) also appeared, with a particularly noticeable growth in the number of author affiliations related to psychology.

The third decade from 1999-2008 saw only limited new sub-discipline affiliations appear, which were restricted to some new Humanities and Liberal Arts sub-disciplines (i.e., cultural studies; communication studies; art, design and music) as well as a few more specific Social and Behavioural Science affiliations related to psychology (i.e., experimental psychology; social psychology; developmental psychology).

Finally, in alignment with the observation that design research seems to be spreading across disciplines, the most recent decade from 2009-2018 has seen the inclusion of a number of new types of author sub-discipline affiliations, across several categories. This expansion is perhaps most evident in the Humanities and Liberal Arts, moving into language and media (e.g., media and visual arts; material culture; language; English; communication and culture; logic; philosophy of science) as well as some specialized sub-disciplines allied to Applied Art, Design and Architecture (i.e., interactive arts and technology; apparel merchandising; interior design) and Social and Behavioural Science (i.e., cognitive neuroscience).

The overall picture over a 40-year period seems to be that of a constant dominance of Technology and Engineering sub-disciplines as well as Applied Arts, Design and Architecture sub-disciplines. This overall domain stability, that was settled early on, is supplemented by the inclusion of new Social and Behavioural Science sub-disciplines (especially in the two periods from 1989-2008) and Humanities and Liberal Arts sub-disciplines (especially from the 2000s onwards).

\subsection{Cross-disciplinary Collaboration}

The analysis of author affiliations in relation to articles published in Design Studies also allows us to explore the level, type and development of interdisciplinary collaboration in the journal, which may be used as an indicator for integration across time in design research. Overall, $16.5 \%$ of Design Studies papers cover author affiliations spanning two or more disciplines (e.g., a scholar with a Technology and Engineering affiliation co-authoring a paper with a scholar having a Social and Behavioural Science affiliation). Most of these cross-disciplinary collaborations span two domains, but a few $(n=15)$ span three or four disciplines. 
Looking across time, the number of cross-disciplinary co-authorships has risen markedly from $3 \%$ in 1979-1988 to $24 \%$ in $2009-2018$. This increasing level is partly driven by the trend of the increasing number of co-authors per research article, which is a global trend not specific to design research (Wutchy, Jones, \& Uzzi, 2007). But even when holding the number of co-authors constant at two, the development towards an increased level of cross-disciplinary co-authorships remains striking (from $5 \%$ in the first period to $20 \%$ in the last period). In descending order of prevalence, the types of cross-disciplinary collaborations take the form of: (i) Technology and Engineering to Applied Arts, Design and Architecture (54), to Companies (29), to Social and Behavioural Science (26), to Humanities and Liberal Arts (16) and to Human Professions and Services (14); followed by (ii) Applied Art, Design and Architecture to Humanities (12) and to Social and Behavioural Science (8). The most prevalent collaborations outside the two largest categories are Social and Behavioral Science to Human Professions and Services (8). Over time, we believe that these cross-disciplinary collaborations are important for theoretical integration and the development of shared understanding and well as being of more general value for spreading disciplinary knowledge of design into new areas. The expansive movement into new scientific areas should not merely be thought of as fragmentation, as it is followed also by movements towards cross-domain integration in the form of an increased level of cross-disciplinary co-authorships.

We contend that our analysis indicates how Design Studies has been instrumental in creating opportunities for cross-disciplinary design research collaborations over the years. A remarkable case-in-point relates to the special issues that have regularly been published in Design Studies based on the 'Design Thinking Research Symposium' (DTRS) series (see Cross, 2018b, for a brief history of this symposium series). DTRS is an interdisciplinary symposium series that brings together academics who have a shared interest in design thinking and design research whilst coming from a diversity of discipline backgrounds, including psychology, anthropology, linguistics, philosophy, architecture, engineering and design studies. The DTRS series provides an international forum for pioneering and state-of-the-art research on design thinking that is focused on the study of design practice from various perspectives (see Dorst, 2018, for a discussion of how the DTRS series has been a major catalyst for research in design thinking).

The history of the DTRS series is also a story of 25 years of shared datasets in design thinking research. This data-sharing approach was initiated in the seminal 'Delft Protocol Workshop' (now also labelled DTRS2), which was organized by Kees Dorst, Nigel Cross and Henri Christiaans at Delft University of Technology in 1994 (see Cross, Christiaans, \& Dorst, 1996; Dorst, 1995) and was based 
around verbal protocol data collected from professional designers in a controlled context. Subsequently, more DTRS events have involved shared data. DTRS7, organized by Janet McDonnell and Peter Lloyd, involved verbal and visual data derived from two sets of professional designers (architects and engineers) working in their natural habitats (Lloyd \& McDonnell, 2009; McDonnell \& Lloyd 2009), and DTRS10, organized by Robin Adams, involved design review conversations in a design education setting (Adams \& Buzzanel, 2016; Adams, Cardella, \& Purzer, 2016). For DTRS11, organized by Bo Christensen, Linden Ball and Kim Halskov, the shared dataset involved video records and audio transcripts of cross-cultural co-creation (Christensen, Ball, \& Halskov, 2017; see also Ball \& Christensen, 2018; Halskov \& Christensen, 2018).

The nature of the shared video-based datasets of design practice allows for a multitude of different research methods to be applied in their analysis. The shared data constitute a common unit of attention for all researchers involved, aiding comprehension across research papers and facilitating discussions among participating design scholars who span a variety of discipline traditions, each drawing upon a rich base of research methods and analytic techniques. That said, shared data do not in themselves compensate fully for a lack of theoretical background knowledge when discussing across academic divides. But over the years, the DTRS series, and the resulting Design Studies special issues, have proven to be a key enabler of cross-disciplinary integration and the exchange of new ideas in design research.

\subsection{The Label 'Design' in University Affiliations}

In order to explore the centrality of design disciplines at universities, we examined whether the label 'design' that appeared in author affiliations in published articles in Design Studies referred to a department (e.g., Department of Design and Technology, Loughborough University) or a faculty (e.g., Melbourne School of Design, University of Melbourne), or whether the label was part of the name of an entire institution (e.g., Parsons School of Design). The data presented in Figure 2 indicate that the prevalence of the design label in affiliations increased from $17.9 \%$ in the period $1979-1988$ to $31.9 \%$ in the period 2008-2019. The percentage of affiliations at department level employing the design label increased from the period 1979-2008, with a slight decline in the most recent period. At faculty level, a large linear increase across time is evident, and the use of the design label at institution level enters in the period 1999-2008 and continues to rise. These observations likely reflect that across time: (i) researchers publishing in Design Studies are increasingly affiliated with university design departments, and (ii) universities have been employing the label design at increasingly higher levels of the organization, now covering more frequently entire faculties and even whole institutions. 
These findings likely reflect the increasing centrality of design research at universities across the four decades analysed.

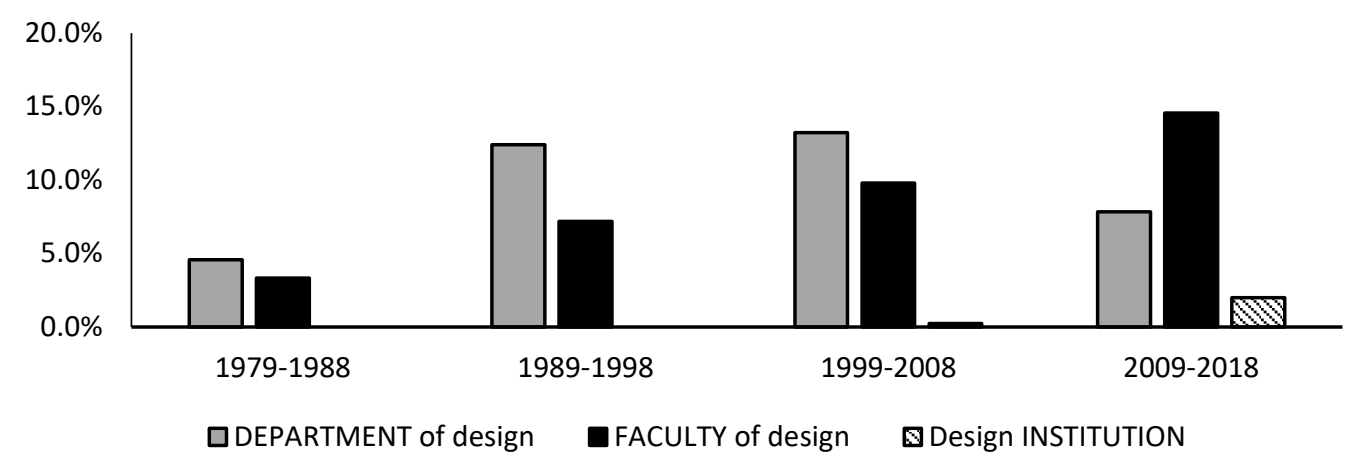

Figure 2. The percentage of Design Studies author affiliations employing the label 'design' by university level (i.e., department vs. faculty vs. institution) as a function of time.

\subsection{Indicators of Design Research Integration and Centrality Based on Citation Patterns}

Citation patterns may serve as useful indicators of discipline integration across time. Previously, Chai and Xiao (2012) provided an in-depth analysis of the literature that was cited by articles published in Design Studies during the period 1996-2010 in order to extract the core and central texts that were being referred to by authors publishing in the journal. Our analysis approach was very different to that of Chai and Xiao in that we instead wished to examine: (i) the most cited papers that had appeared in Design Studies over the past four decades in order to explore the impact of these articles on the wider design research community; and (ii) the citation frequency for selected researchers as indexed by articles published in Design Studies in order to explore the impact of these authors more specifically on the Design Studies research community. Lists of most frequently cited papers are a common way to assess the centrality of research to a particular domain of enquiry and may be useful in gaining an overview of what authors in Design Studies consider to be the most important contributions to design research. Based on Google Scholar and Scopus searches, we extracted a list of the most highly cited Design Studies articles per decade (see Table 2). The authors who feature on the list will be very familiar to design researchers. 
Table 2. Top-5 impact articles in Design Studies by decade, with citations listed from Google Scholar (Scopus in parenthesis); citations extracted July 2019.

\begin{tabular}{|c|c|c|}
\hline & 1979-1988 & Citations \\
\hline 1 & Cross (1982). Designerly ways of knowing & $1141(362)$ \\
\hline 2 & Darke (1979). The primary generator and the design process & $741(203)$ \\
\hline 3 & Bucciarelli (1988). An ethnographic perspective on engineering design & $653(290)$ \\
\hline 4 & Schön (1988). Designing: Rules, types and worlds & $570(208)$ \\
\hline \multirow[t]{2}{*}{5} & Gorb \& Dumas (1987). Silent design & $272(89)$ \\
\hline & 1989-1998 & \\
\hline 1 & Schön \& Wiggins (1992). Kinds of seeing and their functions in designing & $1069(407)$ \\
\hline 2 & Jansson \& Smith (1991). Design fixation & $1064(645)$ \\
\hline 3 & $\begin{array}{l}\text { Suwa \& Tversky (1997). What do architects and students perceive in their design sketches? A } \\
\text { protocol analysis }\end{array}$ & 769 (313) \\
\hline 4 & Purcell \& Gero (1998). Drawings and the design process & $662(286)$ \\
\hline \multirow[t]{2}{*}{5} & Goldschmidt (1994). On visual design thinking: The vis kids of architecture & $588(220)$ \\
\hline & 1999-2008 & \\
\hline 1 & Dorst \& Cross (2001). Creativity in the design process: Co-evolution of problem-solution & $1869(867)$ \\
\hline 2 & Gero \& Kannengiesser (2004). The situated function-behaviour-structure framework & $1174(620)$ \\
\hline 3 & Shah, Vargas-Hernandez \& Smith (2003). Metrics for measuring ideation effectiveness & $930(596)$ \\
\hline 4 & Cross (2004). Expertise in design & $903(471)$ \\
\hline \multirow[t]{2}{*}{5} & $\begin{array}{l}\text { Crilly, Moultrie, \& Clarkson (2004). Seeing things: Consumer response to the visual domain in } \\
\text { product design }\end{array}$ & $878(444)$ \\
\hline & 2009-2018 & \\
\hline 1 & Dorst (2011). The core of 'design thinking' and its application & $888(332)$ \\
\hline 2 & Helms, Vattam, \& Goel (2009). Biologically inspired design: Process and products & $355(192)$ \\
\hline 3 & Lilley (2009). Design for sustainable behaviour: Strategies and perceptions & $288(151)$ \\
\hline 4 & $\begin{array}{l}\text { Xu, Jiao, Yang, Helander, Khalid, \& Opperud (2009). An analytical Kano model for customer } \\
\text { need analysis }\end{array}$ & $264(131)$ \\
\hline 5 & $\begin{array}{l}\text { Miaskiewicz \& Kozar (2011). Personas and user-centered design: How can personas benefit } \\
\text { product design processes? }\end{array}$ & $243(116)$ \\
\hline
\end{tabular}

Exploring the content of the canonical articles on this list will take the reader through a conceptual journey commencing with the role of primary generators in design (Darke, 1979), through the constraining effects of design fixation on design creativity (Jansson \& Smith, 1991) and onwards to problem-solution co-evolution as a key aspect of creative design practice (Dorst \& Cross, 2001). Taking this journey makes it seem like the temporal development of key design research concepts somehow mirrors the path of progression recognizable in many a design process! The most cited papers of the second decade (1989-1999) revolve almost exclusively around design as a visual domain and show a preoccupation with how experienced designers and design students make designs visible and perceive new meanings through such visualizations. In the third decade (19992008) the most cited papers appear to be preoccupied with consolidating frameworks and ways of assessing and measuring designs and design processes, enabling and establishing solid, unifying 
methodological approaches to the study of design. The latest decade (2009-2018) has produced highly-cited works on biologically inspired design as well as globally trending design topics relating to sustainability and user-centeredness.

Finally, the perhaps most obvious observation on domain integration and centrality to be drawn from this list of highly cited papers is the convergence of just two authors at the very top spot of each of the four decades of research: Nigel Cross and Kees Dorst have authored or co-authored the three articles (Cross, 1982; Dorst, 2011; Dorst \& Cross, 2001) that have attracted the most citations for three out of four decades of design research in Design Studies, with Schön and Wiggins (1992) getting the most citations for the remaining decade. Through the decades, Cross and Dorst have continued to produce ground-breaking and highly-cited design research. In addition, they have published key papers that serve as overarching reviews of design research that also encapsulate narratives relating to emerging trends. It can be argued that in Design Studies, these researchers have continually serviced the community with their important function as curators of design knowledge and as commentators on our shared design research journey.

Scholarly voices who might express worries about the possible disintegration and fragmentation of design research through its expansion into neighbouring fields related to design thinking practice should be comforted by the long-term and coherent design perspective evidenced from this shortlist of highly-cited author names. It seems certain that for many years to come the articles of Schön, Cross, and Dorst will continue to provide a short-cut entry point to the essence of what Design Studies has taught us. If one was to point to a single, additional scholar carrying central meaning to design research who is missing from this shortlist, then Herbert Simon (who never published in Design Studies, and thus cannot appear on the highly-cited list) comes readily to mind. Simon and Schön have both been enormously influential to design research, respectively representing a positivist approach to rational problem solving and a constructivist approach to design as reflective practice.

To explore the centrality of these four scholars (Schön, Simon, Cross, Dorst) to design research, we decided to examine their level of author citations in papers published in Design Studies across the decades. We used Scopus to extract all Design Studies articles citing any academic work published by Simon, Schön, Cross or Dorst. We supplemented this analysis with Google Scholar searches for highly-cited individual research papers predating 1996 due to incomplete records in Scopus. This supplementary search strategy may still mean that a few lesser cited research papers published 
before 1996 by the four scholars of interest may not be represented in our analysis. We included only citations from full length Design Studies articles, excluding any other paper formats such as editorials, commentaries and reviews. The results are presented in Figure 3 (Simon and Schön) and Figure 4 (Cross and Dorst), which depict the percentage of Design Studies articles citing each main author by decade.

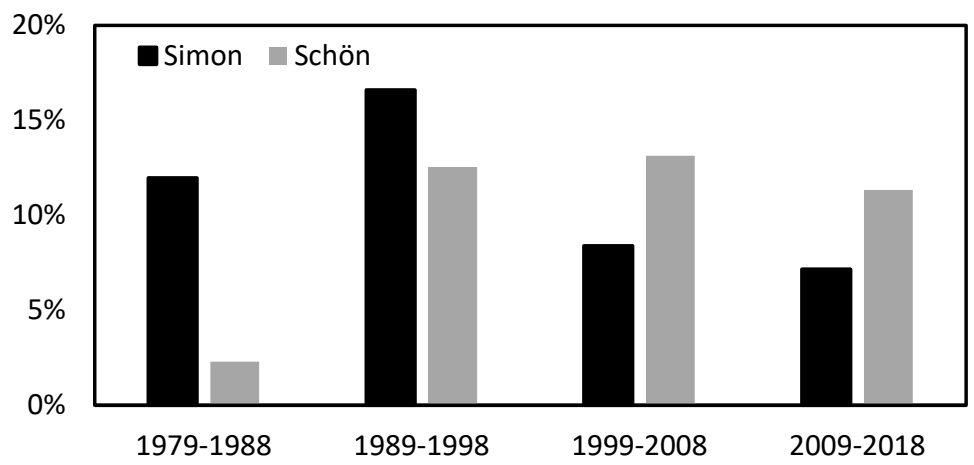

Figure 3. Percentage of Design Studies articles citing Herbert Simon or Donald Schön, by decade.

Figure 3 illustrates that while Simon and Schön have been cited in almost the same percentage of Design Studies papers in total ( $10.6 \%$ vs. $10.3 \%$ of all full papers, respectively), the trend over time is in opposite directions, with a decreasing trend for Simon, but an increasing trend for Schön. A number of papers (26) also cite both authors, with co-citation peaking in the period 1989-1998.

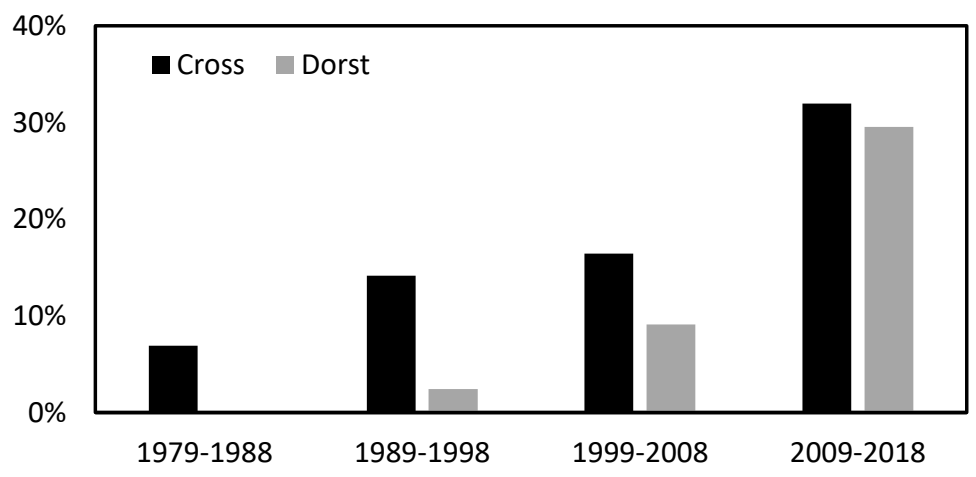

Figure 4. Percentage Design Studies articles citing Nigel Cross or Kees Dorst, by decade.

Figure 4 depicts the frequency of citations in Design Studies articles to Cross and Dorst (18.8\% vs. $12.1 \%$ of all full papers, respectively), and the steep upward progression of citations to both authors across time. The increasing centrality of the two authors for Design Studies is evidenced very 
strikingly by the fact that more than $43 \%$ of Design Studies papers in the most recent period of 2009 2018 cite one or both authors.

\section{Conclusion}

Design research has come a long way in the past four decades. However, in the face of rapidly expanding applications of design concepts into new research disciplines and areas of practice, concerns have been raised as to whether design research may be at risk of diffusion and fragmentation. In this article we have explored the integrative potential arising from the Design Studies research community (e.g., editors, authors and reviewers) through a time-based analysis of citation patterns to articles published in the journal as well as through an examination of the shifting disciplinary affiliations of authors. While our explorations have arguably only provided proxy indicators of integrative potential, we nonetheless believe that the weight and clarity of the evidence leaves little room for pessimism; the Design Studies community has historically proven to be highly capable of expanding to new disciplinary areas through integration whilst simultaneously consolidating the foundation of design research.

The history of design research has seen the term 'design' rise to new levels of centrality at universities, now headlining at the level of departments, faculties and even whole institutions. Considering the stability of scientific disciplines, this development alone tells us that design research is heading toward a very long and stable future. Over the decades, design research has also successfully accommodated new research sub-disciplines into its conceptual base, notably a string of Social and Behavioural Sciences, mainly from the 1990s onwards, as well as a multiplicity of Humanities and Liberal Arts sub-disciplines, especially from the 2000s onwards. The integration of these sub-disciplines is evident in an ever-increasing level of cross-discipline (or cross-faculty) coauthored papers published in Design Studies. The advent of the Design Thinking Research Symposium, with its pioneering approach to cross-disciplinary data-sharing and research collaboration, is yet another indicator of the inclusive and integrative potential of our domain.

In addition, decades of research that has been published in Design Studies have brought to light an array of now canonical concepts and theories, from primary generators, through design fixation and ways of seeing, to abductive reasoning, problem framing, and the co-evolution of problem and solution, to mention just a few key examples. Each decade has added crucial pieces to the puzzle of understanding design and the research community displays no indication of losing its appetite for an openness to fresh ideas. At the same time, as this influx of new ideas has occurred the history of 
Design Studies has seen the canonization of a small number of design scholars who are now firmly positioned as 'must reads' for any newcomer to design research. We are fortunate to have two of these scholars (Cross and Dorst) still curating, commenting on and contributing to ongoing developments in our domain.

From our 'inside-out' perspective we contend that design research appears to be mature, alive-andkicking and very much open for business. Furthermore, it is evident that the design research community that has centred around Design Studies has continued to demonstrate an impressive capacity for stable integration in the face of expanding concepts and definitions and the entry of new sub-disciplines into the frame of design research. To conclude, we profess that our analysis leaves us with very few concerns with respect to either the potential dilution or fragmentation of design research and theorising. We trust that the Design Studies community will be similarly persuaded by our optimistic outlook.

\section{REFERENCES}

Adams, R., \& Buzzanel, P. (Eds.) (2016). Analyzing Design Review Conversations. Purdue, IA: Purdue University Press.

Adams, R. S., Cardella, M., \& Purzer, S. (Eds.) (2016). Design review conversations. Special issue of Design Studies, Vol. 45, No. 1, Part A.

Archer, B. (1979). Design as a discipline. Design Studies, 1, 17-20. doi: 10.1016/0142-694X(79)900231

Ball, L. J., \& Christensen, B. (2018). Designing in the wild. Special issue of Design Studies, Vol. 57, No. 1.

Bremner, C., \& Rodgers, P. (2013). Design without discipline. Design Issues, 29, 4-13. doi: 10.1162/DESI_a_00217

Cash, P. (2018). Developing theory-driven design research. Design Studies, 56, 84-119. doi: 10.1016/j.destud.2018.03.002.

Chai, K. H., \& Xiao, X. (2012). Understanding design research: A bibliometric analysis of Design Studies (1996-2010). Design Studies, 33, 24-43. doi: 10.1016/j.destud.2011.06.004

Christensen, B. T., Ball, L. J., \& Halskov, K. (Eds.) (2017). Analysing Design Thinking: Studies of CrossCultural Co-Creation. London: Taylor \& Francis/CRC Press.

Cross, N. (2007). Forty years of design research. Design Studies, 1, 1-4. doi: 10.1016/j.destud.2006.11.004 
Cross. N. (2018a). Developing design as a discipline. Journal of Engineering Design, 29, 691-708. doi: 10.1080/09544828.2018.1537481

Cross, N. (2018b). A brief history of the Design Thinking Research Symposium series. Design Studies, 57, 160-164. doi: 10.1016/j.destud.2018.03.007

Cross, N., Christiaans, H., \& Dorst, K. (Eds.) (1996). Analysing Design Activity. Chichester, UK: John Wiley \& Sons.

Darke, J. (1979). The primary generator and the design process. Design Studies, 1, 36-44. doi: 10.1016/0142-694X(79)90027-9

Dorst, K. (2011). The core of 'design thinking' and its application. Design Studies, 32, 521-532. doi: 10.1016/j.destud.2011.07.006

Dorst, K. (Ed.) (1995). Analysing design activity. Special issue of Design Studies, Vol. 16, No. 2.

Dorst, K. (2018). DTRS: A catalyst for research in design thinking. Design Studies, 57, 156-159. doi: 10.1016/j.destud.2018.03.005

Dorst, K., \& Cross, N. (2001). Creativity in the design process: Co-evolution of problemsolution. Design Studies, 22, 425-437. doi: 10.1016/S0142-694X(01)00009-6

Friedman, K. (2003). Theory construction in design research: Criteria, approaches, and methods. Design Studies, 24, 507-522. doi: 10.1016/S0142-694X(03)00039-5

Gardner, H. (1987). The Mind's New Science: A History of the Cognitive Revolution. New York: Basic Books.

Halskov, K., \& Christensen, B. T. (Ed.) (2018). Designing across cultures. Special issue of CoDesign, Vol. 14, No. 2.

Jansson, D. G., \& Smith, S. M. (1991). Design fixation. Design studies, 12, 3-11. doi: 10.1016/0142$694 \times(91) 90003-\mathrm{F}$

Jones \& Thornley, 1963

Jones, J. C., \& Thornley, D. G. (Eds.) (1963). Conference on Design Methods. Oxford, UK: Pergamon Press.

Liedtka, J. (2015). Perspective: Linking design thinking with innovation outcomes through cognitive bias reduction. Journal of Product Innovation Management, 32, 925-938. doi:

10.1111/jpim.12163

Lloyd, P., \& McDonnell, J. (Eds.) (2009). Values in the design process. Special issue of Design Studies, Vol. 29, No. 2.

McDonnell, J., \& Lloyd, P. (Eds.) (2009). About: Designing - Analysing Design Meetings. London, UK: Taylor \& Francis.

Simon, H. A. (1969). The Sciences of the Artificial. Cambridge, MA: MIT Press. 
Wuchty, S., Jones, B. F., \& Uzzi, B. (2007). The increasing dominance of teams in production of knowledge. Science, 316, 1036-1039. doi: 10.1126/science.1136099 